\title{
G s-mitur \\ Establishment of a Veno-venous Extracorporeal Membrane Oxygenation in a Rat Model of acute Respiratory Distress Syndrome
}

\section{Yongnan Li}

Department of Cardiac Surgery, Lanzhou University Second Hospital, Lanzhou University, Lanzhou, China. Laboratory of Extracorporeal Life Support, Lanzhou University Second Hospital, Lanzhou University, Lanzhou, China

\section{Jian Huang}

Department of Cardiac Surgery, Lanzhou University Second Hospital, Lanzhou University, Lanzhou, China. Laboratory of Extracorporeal Life Support, Lanzhou University Second Hospital, Lanzhou University, Lanzhou, China

\section{Rongzhi Zhang}

Department of Anesthesiology, Lanzhou University Second Hospital, Lanzhou University, Lanzhou, China

\section{Shixiong Wang}

Department of Cardiac Surgery, Lanzhou University Second Hospital, Lanzhou University, Lanzhou, China

\section{Xingdong Cheng}

Department of Cardiac Surgery, Lanzhou University Second Hospital, Lanzhou University, Lanzhou, China. Laboratory of Extracorporeal Life Support, Lanzhou University Second Hospital, Lanzhou University, Lanzhou, China

\section{Pengbin Zhang}

Department of Cardiac Surgery, Lanzhou University Second Hospital, Lanzhou University, Lanzhou, China. Laboratory of Extracorporeal Life Support, Lanzhou University Second Hospital, Lanzhou University, Lanzhou, China

\section{Kerong Zhai}

Department of Cardiac Surgery, Lanzhou University Second Hospital, Lanzhou University, Lanzhou, China. Laboratory of Extracorporeal Life Support, Lanzhou University Second Hospital, Lanzhou University, Lanzhou, China

\section{Wei Wang}

Department of Cardiopulmonary Bypass, Lanzhou University Second Hospital, Lanzhou University, Lanzhou, China

\section{Debin Liu}


Department of Cardiac Surgery, Lanzhou University Second Hospital, Lanzhou University, Lanzhou, China

\section{Bingren Gao ( $\nabla$ bingrengao@foxmail.com )}

Lanzhou University Second Hospital

\section{Methodology}

Keywords: Acute respiratory distress syndrome, Veno-venous extracorporeal membrane oxygenation, Double lumen cannula, Oleic acid, Rat model

Posted Date: December 2nd, 2020

DOl: https://doi.org/10.21203/rs.3.rs-117486/v1

License: (c) (i) This work is licensed under a Creative Commons Attribution 4.0 International License. Read Full License 


\section{Abstract}

Background: Venovenous extracorporeal membrane oxygenation (VV-ECMO) is now considered a reasonable option to salvage acute respiratory distress syndrome (ARDS). However, we lack a rodent model for experimental studies. This study was undertaken to establish an animal model of VV-ECMO in ARDS rats.

Methods: Fifteen Sprague-Dawley (SD) rats $(350 \pm 50 \mathrm{~g})$ were used in this study. Using a rat model of oleic acid (OA)-induced ARDS, VV-ECMO was established through bi-caval cannulation of the right jugular vein for venous drainage and venous reinfusion with a specially designed three-cavity catheter.

Continuous arterial pressure monitoring was implemented by using a catheter through cannulation of the right femoral artery. The central temperature was monitored with a rectal probe. Arterial blood gas monitoring was implemented by a blood gas analyzer at three-time points: at baseline, 1-hour (after OA modeling), and 3.5-hour (after VV-ECMO support). Lung tissue and bronchoalveolar lavage fluid were harvested respectively for protein concentration and pulmonary histologic evaluation to confirm the alleviation of lung injury during VV-ECMO.

Results: Following ARDS induced by OA, ten rats were successfully established on VV-ECMO without failure, and survived from the ECMO procedure. VV-ECMO alleviated lung injury and restored adequate circulation for the return of lung function and oxygen. VV-ECMO was associated with decreased lung injury score, wet/dry weight ratio, and fluid leakage into airspaces.

Conclusion: We have established a reliable, economical, and functioning ARDS rat model of VV-ECMO.

\section{Background}

Extracorporeal membrane oxygenation (ECMO) is a life support technique that provides cardiorespiratory support in patients with severe respiratory and cardiac failure [1]. There are two main configurations for an ECMO circuit: veno-arterial and veno-venous [1, 2]. The veno-venous ECMO (VV-ECMO) configuration is preferred in cases of respiratory failure with preserved cardiac function [3]. However, VV-ECMO is thought to play a key role in acute respiratory distress syndrome (ARDS), but its exact role is unclear and suitable animal models are needed to answer this question. Here, we describe a novel VV-ECMO technique using bi-caval cannulation in an oleic acid (OA)-induced rat model of ARDS. This rat model restores respiratory function and offers a tool to study physiological and molecular changes in lung disease during VV-ECMO.

\section{Methods}

\section{Animals}

Fifteen Sprague-Dawley (SD) rats (350 $\pm 50 \mathrm{~g})$ were used for all the experiments and randomly divided into 2 groups: OA group $(n=3)$ and VV-ECMO group $(n=12)$. All animals received humane care in compliance with the 'Principles of laboratory animal care' formulated by the National Society for Medical 
Research and the 'Guide for the care and use of laboratory animal resources' published by the US National Institute of Health (NIH publication No. 85-23, revised 1996). The following experimental protocol was approved by the local Ethical Committee of Lanzhou Second Hospital, Lanzhou University, Gansu.

\section{Induction of lung injury}

ARDS and impaired gas exchange were modeled in rats by intravenous administration of $99 \%$ pure OA (Sigma-Aldrich) as previously described [4,5]. OA and $9 \mathrm{~mL}$ physiologic saline solution (negative control) were given at a final concentration of $25 \mathrm{mg} / \mathrm{mL}$. $100 \mathrm{mg} / \mathrm{kg}$ of $O A$ was administered via the femoral vein at an infusion rate of $20 \mathrm{mg} / \mathrm{kg} / \mathrm{min}$ over 5 mins to avoid sudden death due to massive pulmonary embolism [6].

\section{Extracorporeal membrane oxygenation circuit}

The ECMO circuit consisted of a peristaltic pump (PreFluid Co. Ltd.) (Figure 1A), membrane oxygenator and tubing (Xijing Medical Co. Ltd.) (Figure 1B), 24G catheter (Figure 1C), and a 5.5 F specially designed three-cavity catheter (Figure 1D). In contrast to cardiopulmonary bypass circuits, this circuit lacked a reservoir unit, minimizing blood-air contact [7-9]. The membrane oxygenator (oxygenation area $0.02 \mathrm{~m}^{2}$ ) used during this procedure was specifically designed for this study. The entire circuit priming volume was $6 \mathrm{~mL}$, with the membrane oxygenator constituting $3 \mathrm{~mL}$. Priming was done using 6\% HES130/0.4 (Fresenius Co. Ltd.) $(3 \mathrm{~mL})$ and Ringer's solution $(3 \mathrm{~mL})$, without blood.

\section{Surgical procedure}

Rats were anesthetized using $2 \%$ sevoflurane to achieve stable anesthesia during the entire operation. Initial ventilatory parameters included 70-75 breaths/min, a tidal volume of $6 \mathrm{~mL} / \mathrm{kg}$, a 1:2 I:E ratio, and a $3 \mathrm{cmH}_{2} \mathrm{O}$ positive end-expiratory pressure (PEEP). A 24-gauge catheter was inserted in the right femoral artery for continuous arterial pressure monitoring. Heparin was administered at $300 \mathrm{U} / \mathrm{kg}$. The right jugular vein was exposed and cannulated with a $5.5 \mathrm{~F}$ specially designed three-cavity catheter. Central temperature was monitored using a rectal probe and maintained at $36 \pm 0.5^{\circ} \mathrm{C}$ using a heating lamp. Venous return was exclusively drained using a roller pump. ECMO was established at a flow rate of 80-90 $\mathrm{mL} / \mathrm{kg} / \mathrm{min}$. Upon reaching optimal flow rate, it was adjusted to a level that could maintain desired arterial pressure. Gas flow $\left(90 \% \mathrm{O}_{2}\right)$ was initiated at around $80-100 \mathrm{~mL} / \mathrm{min}$ and adjusted in terms of sweep rate and $\mathrm{FiO}_{2}$ to maintain blood gasses within the physiological range. $1 \mathrm{~mL}$ of sodium bicarbonate is usually added to the circuit during ECMO to maintain acid-base balance. All volume substituting or buffering solutions were given via the femoral artery. After $3 \mathrm{~h}$, the animals were weaned off ECMO and the remaining priming volume re-infused (Additional file video 1). 


\section{Blood gas analysis, protein concentration in bronchoalveolar lavage, and histology}

To assess the oxygenation and metabolic states of the animals during VV-ECMO (EG7 ${ }^{+}$, iStar, Abbott Co. Ltd.), blood gas analysis (BGA) was done on blood samples from the femoral artery. Femoral arterial blood gas measurements were done at 0 (T0, baseline), $1 \mathrm{~h}$ ( $\mathrm{T} 1$, after OA modeling), and $3.5 \mathrm{~h}$ ( $\mathrm{T} 2$, after VV-ECMO support). At the end of the experiment, bronchoalveolar lavage fluid (BALF) was harvested by lavaging the lungs with $2.5 \mathrm{~mL}$ PBS $1 \mathrm{X}$ and BALF protein concentration determined using BCA analysis. The lung was collected and fixed in $4 \%$ paraformaldehyde for $24 \mathrm{~h}$ at $4{ }^{\circ} \mathrm{C}$. Four micrometer paraffin sections were stained with hematoxylin and eosin (H\&E), and organ damaged evaluated histologically. Lung injury score was evaluated using a modified, previously described scoring system [6]. Various degrees of lung injury score were designated degree $0,1,2$, and 3 for mild, moderate, and severe edema, respectively. Similar scoring was used for inflammatory cell infiltration, with degree $0,1,2$, and 3 , indicating none, mild, moderate, and severe cellular infiltration, respectively. Histopathological assessment was done by several blinded laboratory assistants with each giving scores for edema and cell infiltration. The individual edema and cell filtration scores were then summed to obtain a final score ranging from $0-6$.

\section{Results}

After a $1 \mathrm{~h}$ OA treatment, rats developed hypoxemia $\left(\mathrm{PaO}_{2} / \mathrm{FiO}_{2}<300 \mathrm{mmHg}\right)$. Ten rats were successfully put on VV-ECMO, with all surviving the ECMO procedure. One rat died immediately after OA injection, probably from pulmonary embolism due to rapid OA administration. Another died from massive bleeding after ruptured jugular vein during catheter insertion. Figure 2 shows VV-ECMO's hemodynamic data. Mean arterial pressure significantly reduced $1 \mathrm{~h}$ after $\mathrm{OA}$ administration relative to pre-operation, but remained stable during VV-ECMO and 30 min after weaning from ECMO.

Table 1 summarizes the blood gas and biochemical parameters of the $\mathrm{VV}$-ECMO procedure. $\mathrm{PaO}_{2}, \mathrm{PaCO}_{2}$ and $\mathrm{SaO}_{2}$ were stable during $\mathrm{VV}$-ECMO, indicating attenuated OA-induced systemic hypoxemia. $\mathrm{pH}$, base excess and $\mathrm{HCO}_{3}{ }^{-}$also remained stable throughout the experiment. Relative to pre-ECMO, $\mathrm{Hct}$ and $\mathrm{Hb}$ significantly reduced but remained stable during VV-ECMO. No excessive blood loss was noted, which was consistent with the relatively stable $\mathrm{Hct}$ and $\mathrm{Hb}$ values. These findings were comparable to our previous data, and the lower values were due to hemodilution. To ensure proper membrane oxygenator function, blood sampling was done immediately before, and after oxygenation following VV-ECMO initiation (Fig. 3). Pre-oxygenator $\mathrm{PO}_{2}(40 \pm 7 \mathrm{mmHg})$ and post-oxygenator $\mathrm{PO}_{2}(490 \pm 48 \mathrm{~mm} \mathrm{Hg})$ increased significantly $(p=<0.0001)$, indicating excellent oxygenation capacity of our membrane oxygenator, and minimal recirculation. There was a significant increase in $\mathrm{PaO}_{2} / \mathrm{FiO}_{2}$ after $3 \mathrm{~h}$ of $\mathrm{VV}$ ECMO. 
Table 1

Metabolic changes pre and post VV-ECMO resuscitation of acute lung injury

\begin{tabular}{|llll|}
\hline Biochemical parameter & $\mathrm{TO}$ & $\mathrm{T} 1$ & $\mathrm{~T} 2$ \\
\hline $\mathrm{pH}$ & $7.319 \pm 0.126$ & $7.303 \pm 0.053$ & $7.288 \pm 0.127$ \\
\hline $\mathrm{PaO}_{2}(\mathrm{mmHg})$ & $169 \pm 21$ & $110 \pm 15^{\#}$ & $348 \pm 58^{*}$ \\
\hline $\mathrm{PaO}_{2} / \mathrm{FiO}_{2}(\mathrm{mmHg})$ & $423 \pm 51$ & $275 \pm 38^{\#}$ & $387 \pm 64^{*}$ \\
\hline $\mathrm{PaCO}_{2}(\mathrm{mmHg})$ & $38 \pm 10$ & $49 \pm 6$ & $45 \pm 8$ \\
\hline $\mathrm{SaO}_{2}(\%)$ & $99.5 \pm 0.5$ & $97.5 \pm 1.3^{\#}$ & $99.1 \pm 0.7^{*}$ \\
\hline $\mathrm{BE}^{*}$ & $0 \pm 4$ & $-1 \pm 3$ & $-2 \pm 1$ \\
\hline $\mathrm{HCO}_{3}{ }^{-}(\mathrm{mmol} / \mathrm{l})$ & $24.5 \pm 3.4$ & $24.5 \pm 1.9$ & $24.9 \pm 3.9$ \\
\hline $\mathrm{TCO}_{2}(\mathrm{mmol} / \mathrm{l})$ & $24.3 \pm 6.8$ & $26.8 \pm 3.3$ & $23.0 \pm 3.9$ \\
\hline $\mathrm{Na}^{+}(\mathrm{mmol} / \mathrm{l})$ & $138 \pm 2$ & $140 \pm 3$ & $142 \pm 5$ \\
\hline $\mathrm{K}^{+}(\mathrm{mmol} / \mathrm{l})$ & $4.2 \pm 0.6$ & $4.8 \pm 0.4$ & $4.6 \pm 0.6$ \\
\hline $\mathrm{Ca}^{2+}(\mathrm{mmol} / \mathrm{l})$ & $1.37 \pm 0.09$ & $1.37 \pm 0.07$ & $1.25 \pm 0.17$ \\
\hline $\mathrm{Hct}(\%)$ & $40.4 \pm 2.0$ & $41.8 \pm 3.3$ & $29.2 \pm 2.6^{*}$ \\
\hline $\mathrm{Hb}^{*}(\mathrm{~g} / \mathrm{dL})$ & $14.4 \pm 0.6$ & $14.5 \pm 1.0$ & $12.3 \pm 1.4^{*}$ \\
\hline$\# p<0.05, \mathrm{~T} 1 \mathrm{vs} . \mathrm{T0}{ }^{*} p<0.05, \mathrm{~T} 2 \mathrm{vs} . \mathrm{T} 1$. & & \\
\hline
\end{tabular}

Histological analysis revealed severe diffuse alveolar damage, the pathologic hallmark of ARDS, with presence of hyaline membranes, alveolar wall thickening, and extensive infiltration by inflammatory cells (Fig. 4A). However, treating OA-injected rats with VV-ECMO $1 \mathrm{~h}$ after OA injection ameliorated virtually all major histopathologic changes induced by OA in the lungs (Fig. 4B). VV-ECMO was associated with decreased lung injury score (Fig. 4C), wet/dry weight ratio (Fig. 4D), and fluid leakage into airspaces (Fig. 4E), illustrating that VV-ECMO alleviates OA-induced ARDS.

\section{Discussion}

Based on our previously described rat model of CPB [7-9], we have developed a stable VV-ECMO method in a rat model of ARDS. After $\mathrm{OA}$ modeling, $\mathrm{PaO}_{2} / \mathrm{FiO}_{2}$ rapidly reduced, indicating lung injury [6]. After a $3 \mathrm{~h}$ period of support, VV-ECMO was weaned and the resuscitated lung's ability support oxygen supply assessed. This study offers a reliable, reproducible, and economical model of physiological changes that occur during VV-ECMO. 
Despite advances in our understanding of ARDS and its treatment, its mortality rate remains high [10]. VV-ECMO supports whole blood oxygenation and carbon dioxide elimination and has the potential to rescue ARDS patients with refractory hypoxemia or those unable to tolerate conventional therapy $[1,11]$. To better study the effects of VV-ECMO, reliable animal models are needed [12]. Rats have multiple advantages as animal models of human conditions, including anatomical structures that are almost identical to human ones, small volume, low cost, and easy handling relative to large animal models [13]. Thus, we used rats to create the first rodent model of VV-ECMO and used it for successful resuscitation after OA-induced lung injury. OA administration recapitulated basic ARDS characteristics, including hypoxemia $[4,5]$. VV-ECMO was offered with minimal recirculation, rapidly correcting hypoxemia and improving survival. This rodent model more closely copies real clinical situations relative to existing models.

Animal models of bi-caval ECMO are rare. To our knowledge, there are no reports on bi-caval double lumen ECMO using rat models, making this a novel approach. Venous drainage is crucial for successful establishment of VV-ECMO. Previous studies reported that drainage of venous blood by gravity achieves adequate perfusion [12]. Here, venous drainage was achieved through active roller-head assist. The specially designed venous cannula was then inserted into the jugular vein and moved towards the right atrium into the inferior vena cava, allowing a perfusion flow rate of $80-90 \mathrm{~mL} / \mathrm{kg} / \mathrm{min}$. Normal rat cardiac output ranges from $160-180 \mathrm{~mL} / \mathrm{kg} / \mathrm{min}$ [13]. Thus, on average, we achieved a VV-ECMO flow of $50 \%$ rat cardiac output. Relative to VA-ECMO, VV-ECMO requires lower blood flow because excessive perfusion of right atrium causes heart failure due to excess blood pressure in right ventricle [14]. Clinically, a VV-ECMO flow of $50-75 \%$ of the cardiac output is sufficient for adequate oxygenation in ARDS patients on mechanical ventilation [11]. Unnecessary increases in VV-ECMO flow rate may cause hemolysis damage, and unnecessary recirculation of the main portion of venous blood between IVC and SVC [15]. Furthermore, we observed that increasing ECMO flow rate caused excessive negative pressure, which could cause air suction into intubation sites.

Hemodynamic and blood gas analyses revealed that these parameters fluctuate within an acceptable range. Relative to pre-ECMO, $\mathrm{Hct}$ and $\mathrm{Hb}$ decreased significantly, mainly due to dilution of the priming solution. However, compared to past studies [7-9], we reduced overall priming volume to $6 \mathrm{~mL}$ without blood to avoid adverse effects from transfusion. In our clinical experience, routine addition of sodium bicarbonate during bypass achieves satisfactory blood gas parameters. In general, our model of VVECMO had excellent results in ARDS rats. Our study offers a valuable model for further physiological research into potential organ protection and complications from VV-ECMO, and serve as a useful tool for future lung disease studies.

\section{Conclusions}

We have established a reliable and economical VV-ECMO approach using a rat model of ARDS. Biochemical analysis show that despite lung injury, our VV-ECMO circuit restored adequate circulation to 
restore lung function and oxygen. This protocol demonstrates the detailed techniques, physiological observations, and blood gas analysis required for successful VV-ECMO.

\section{List Of Abbreviations}

ECMO: Extracorporeal membrane oxygenation; VV-ECMO: Veno-venous extracorporeal membrane oxygenation; ARDS: Acute respiratory distress syndrome; OA: oleic acid: SD rat: Sprague-Dawley rat; PEEP: positive end-expiratory pressure; BGA: Blood gas analysis; BALF: Bronchoalveolar lavage fluid; H\&E: Hematoxylin and eosin.

\section{Declarations}

\section{Ethics approval and consent to participate}

All animals received humane care in compliance with the 'Principles of laboratory animal care' formulated by the National Society for Medical Research and the 'Guide for the care and use of laboratory animal resources' published by the US National Institute of Health (NIH publication No. 85-23, revised 1996). The following experimental protocol was approved by the local Ethical Committee of Lanzhou Second Hospital, Lanzhou University, Gansu.

\section{Availability of data and materials}

The datasets used and/or analyzed during the current study are available from the corresponding author on reasonable request.

\section{Consent for publication}

Written informed consent for publication was obtained from all participants.

\section{Competing interests}

The authors declare that they have no competing interests

\section{Funding}

This study was supported by Project funded by China Postdoctoral Science Foundation (2020M683610), and the Cuiying Scientific and Technological Innovation Program of Lanzhou University Second Hospital (CY2019-QN01, CY2017-MS07, CY2017-BJ01). 


\section{Authors' contributions}

Conception of the study: YNL, JH, DBL and BRG. Design of the study: YNL, JH, RZZ, XDC, PBZ, and BRG. Data acquisition and analysis: YNL, JH, SXW, KRZ, WW and BRG. Drafting the manuscript: YNL, DBL, and BRG. Critical revision of the manuscript: YNL, JH, RZZ, DBL and BRG. All authors read and approved the final manuscript.

\section{Acknowledgements}

We thank Zhang Xuan for critical reading of the manuscript and English editing.

\section{References}

1. Combes $A$, Schmidt $M$, Hodgson $C L$, et al. Extracorporeal life support for adults with acute respiratory distress syndrome. Intensive Care Med. 2020: 1-13.

2. Guglin M, Zucker MJ, Bazan VM, et al. Venoarterial ECMO for Adults: JACC Scientific Expert Panel. J Am Coll Cardiol. 2019; 73: 698-716.

3. Combes A, Peek GJ, Hajage D, et al. ECMO for severe ARDS: systematic review and individual patient data meta-analysis. Intensive Care Med. 2020; 46: 2048-2057.

4. Matute-Bello G, Frevert CW, Martin TR. Animal models of acute lung injury. Am J Physiol Lung Cell Mol Physiol. 2008; 295: L379-L399.

5. Gonçalves-de-Albuquerque CF, Silva AR, Burth P, Castro-Faria MV, Castro-Faria-Neto HC. Acute Respiratory Distress Syndrome: Role of Oleic Acid-Triggered Lung Injury and Inflammation. Mediators Inflamm. 2015; 2015: 260465.

6. Chen HI, Hsieh NK, Kao SJ, Su CF. Protective effects of propofol on acute lung injury induced by oleic acid in conscious rats. Crit Care Med. 2008; 36: 1214-1221.

7. Liu M, Zeng Q, Li Y, Liu G, Ji B. Neurologic recovery after deep hypothermic circulatory arrest in rats: A description of a long-term survival model without blood priming. Artif Organs. 2019; 43: 551-560.

8. Liu Y, Xing J, Li Y, Luo Q, Su Z, Zhang X, Zhang H. Chronic hypoxia-induced Cirbp hypermethylation attenuates hypothermic cardioprotection via down-regulation of ubiquinone biosynthesis. Sci Transl Med. 2019; 11: eaat8406.

9. Li Y, Liu M, Gao S, et al. Cold-inducible RNA-binding protein maintains intestinal barrier during deep hypothermic circulatory arrest. Interact Cardiovasc Thorac Surg. 2019; 29: 583-591.

10. Bellani G, Laffey JG, Pham T, et al. Epidemiology, patterns of care, and mortality for patients with acute respiratory distress syndrome in intensive care units in 50 countries. JAMA 2016; 315: 788.

11. Schmidt M, Franchineau G, Combes A. Recent advances in venovenous extracorporeal membrane oxygenation for severe acute respiratory distress syndrome. Curr Opin Crit Care. 2019; 25: 71-76. 
12. Millar JE, Bartnikowski N, von Bahr V, Malfertheiner MV, et al. Extracorporeal membrane oxygenation (ECMO) and the acute respiratory distress syndrome (ARDS): a systematic review of pre-clinical models. Intensive Care Med Exp. 2019; 7: 18.

13. Ali AA, Downey P, Singh G, et al. Rat model of veno-arterial extracorporeal membrane oxygenation. J Transl Med. 2014; $12: 37$.

14. Madrahimov N, Khalikov A, Boyle EC, et al. Veno-Venous Extracorporeal Membrane Oxygenation in a Mouse. J Vis Exp. 2018; 140: 58146.

15. Natanov R, Khalikov A, Gueler F, et al. Four hours of veno-venous extracorporeal membrane oxygenation using bi-caval cannulation affects kidney function and induces moderate lung damage in a mouse model. Intensive Care Med Exp. 2019; 7: 72.

\section{Figures}



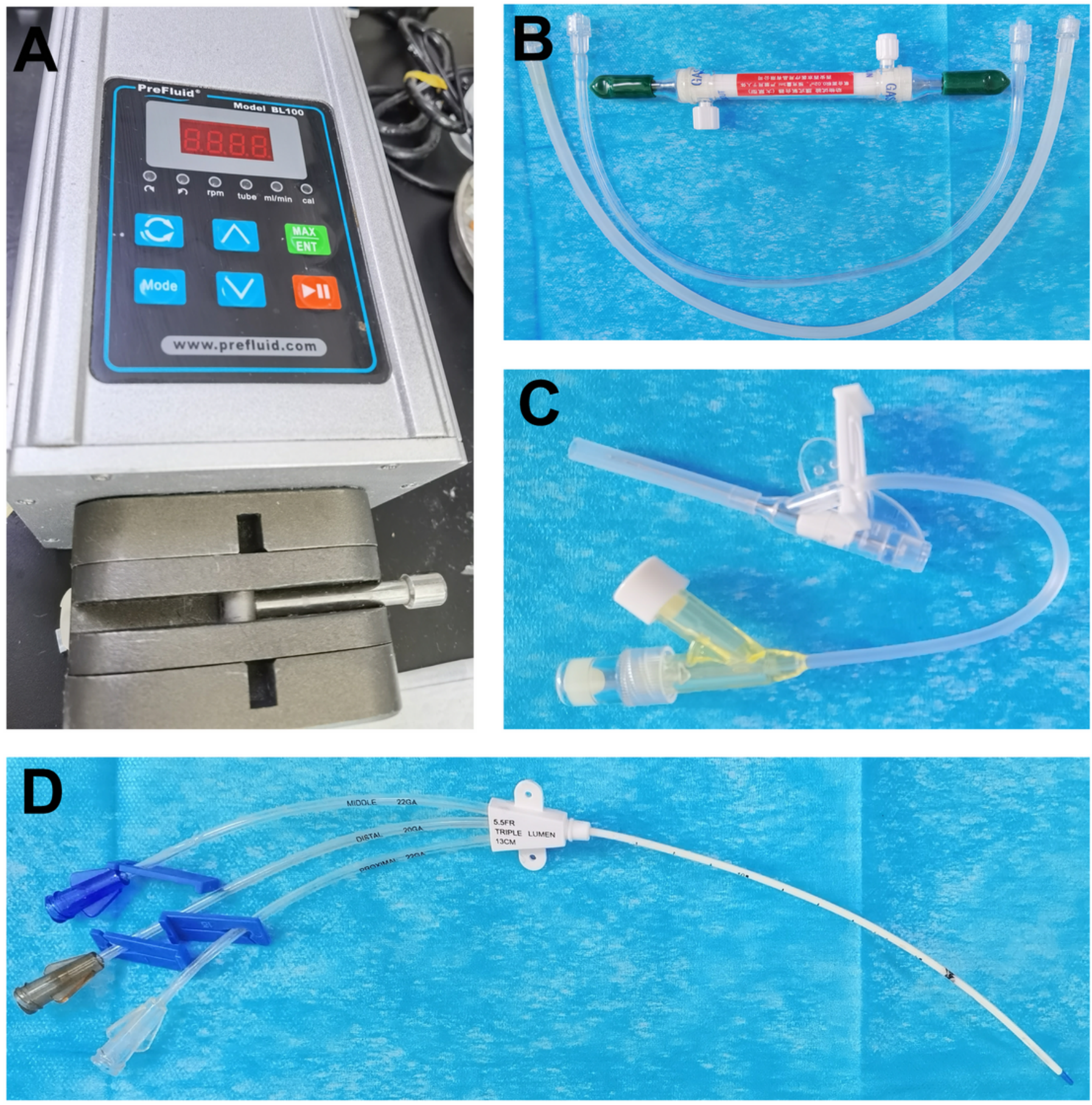

Figure 1

VV-ECMO circuit. Peristaltic pump (A), membrane oxygenator and tubing (B), $24 \mathrm{G}$ femoral arterial cannula (C), and 5.5 F specially designed three-cavity catheter (D). 

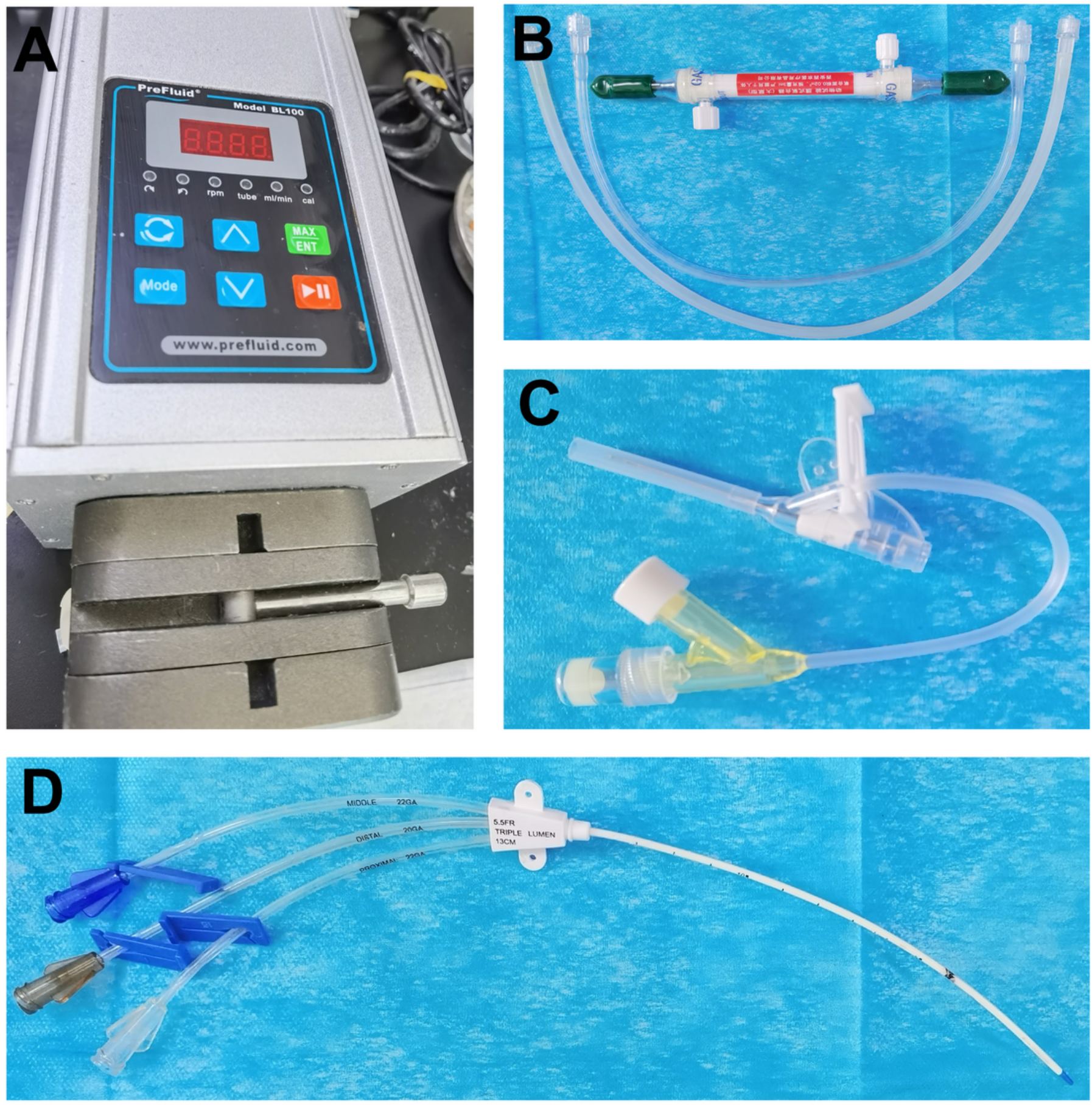

Figure 1

VV-ECMO circuit. Peristaltic pump (A), membrane oxygenator and tubing (B), $24 \mathrm{G}$ femoral arterial cannula (C), and 5.5 F specially designed three-cavity catheter (D). 

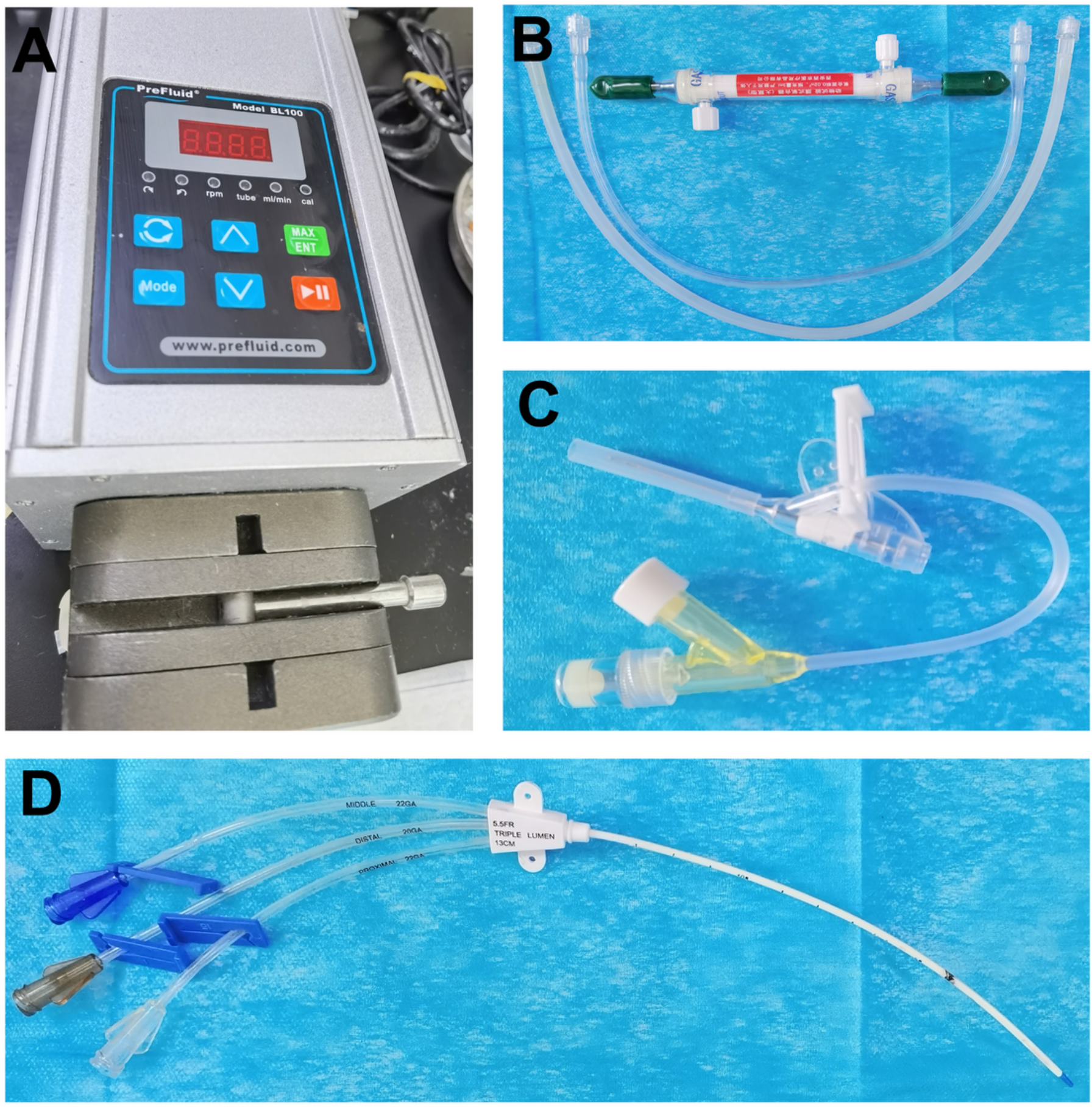

Figure 1

VV-ECMO circuit. Peristaltic pump (A), membrane oxygenator and tubing (B), $24 \mathrm{G}$ femoral arterial cannula (C), and 5.5 F specially designed three-cavity catheter (D). 

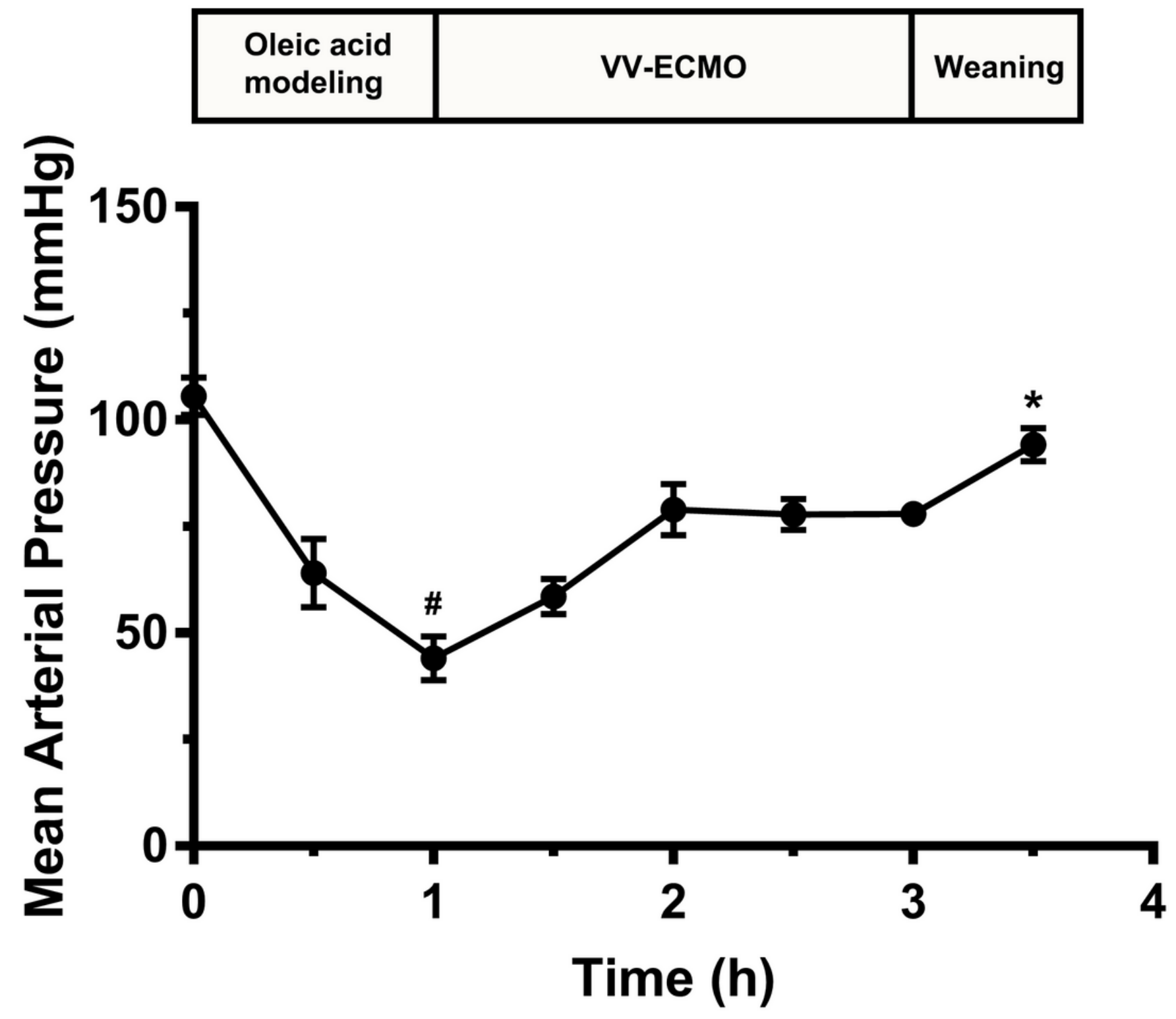

Figure 2

Time course of changes in mean arterial pressure $(n=10)$. Oleic acid $(O A)$ caused severe systemic hypotension. Hypotension was significantly increased following VV-ECMO treatment. \#p < 0.05, T1 vs. T0; $* p<0.05$, T2 vs. T1. 

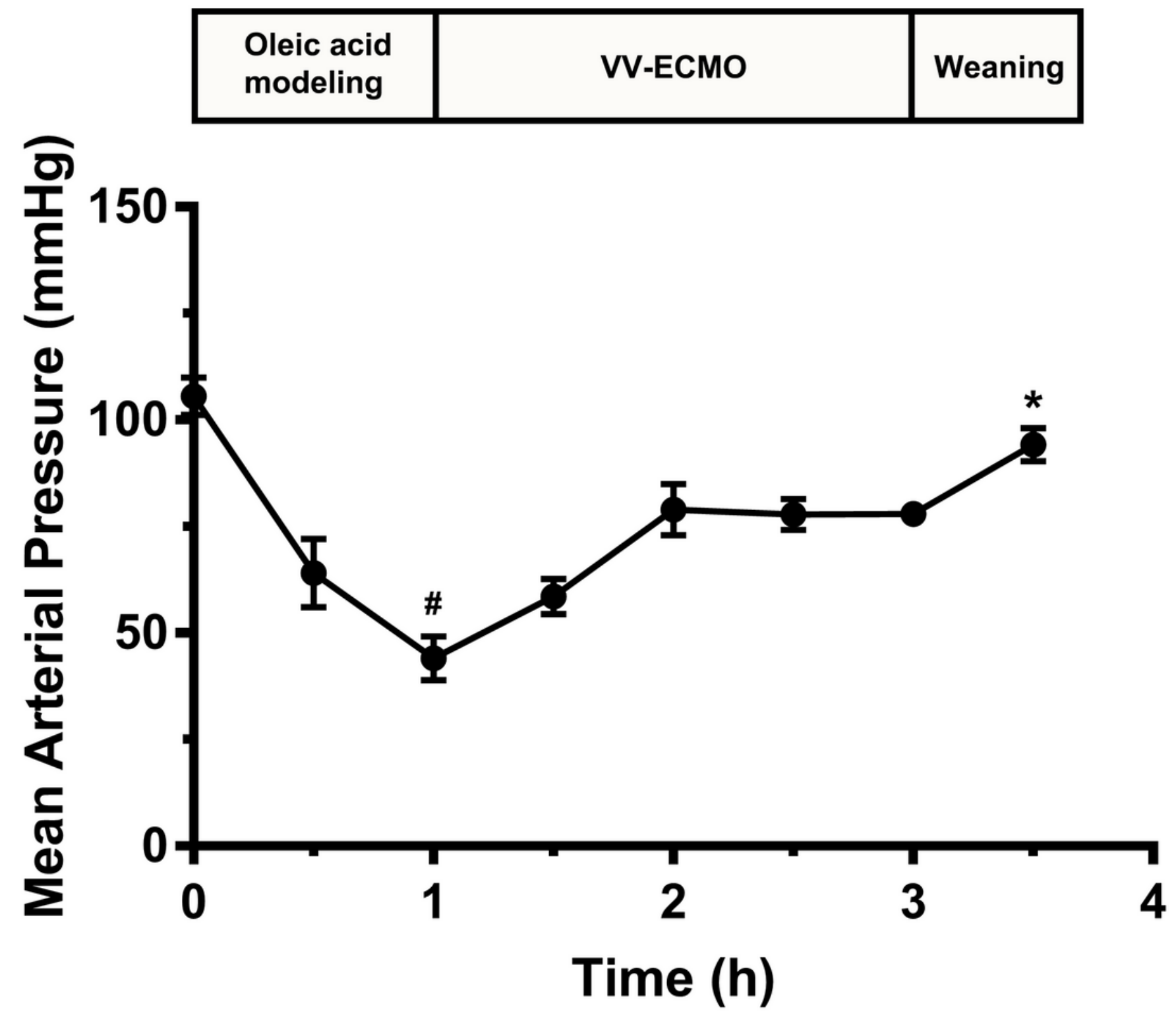

Figure 2

Time course of changes in mean arterial pressure $(n=10)$. Oleic acid $(O A)$ caused severe systemic hypotension. Hypotension was significantly increased following VV-ECMO treatment. \#p < 0.05, T1 vs. T0; $* p<0.05$, T2 vs. T1. 


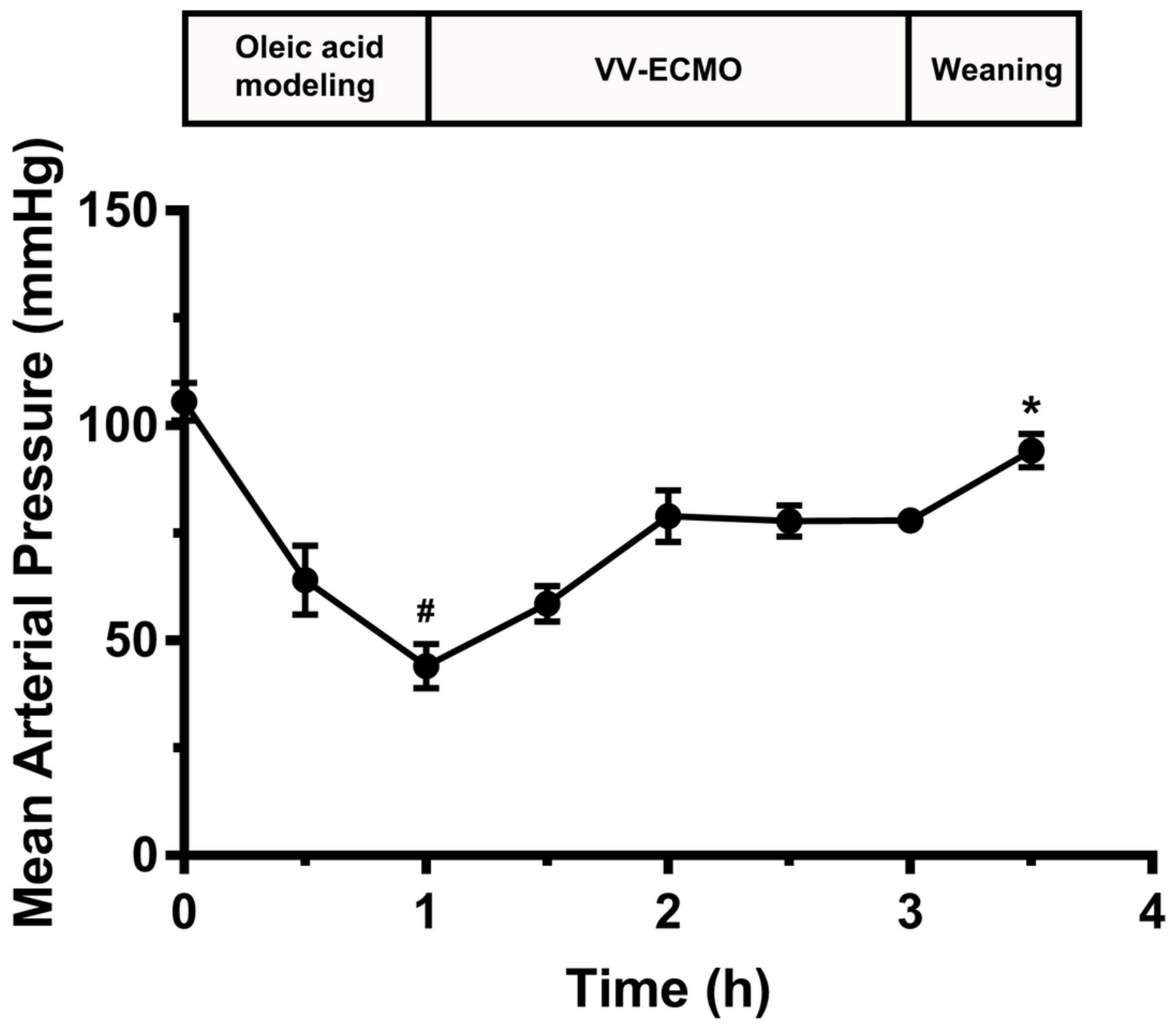

Figure 2

Time course of changes in mean arterial pressure $(n=10)$. Oleic acid $(O A)$ caused severe systemic hypotension. Hypotension was significantly increased following VV-ECMO treatment. \#p < 0.05, T1 vs. T0; $* p<0.05$, T2 vs. T1. 

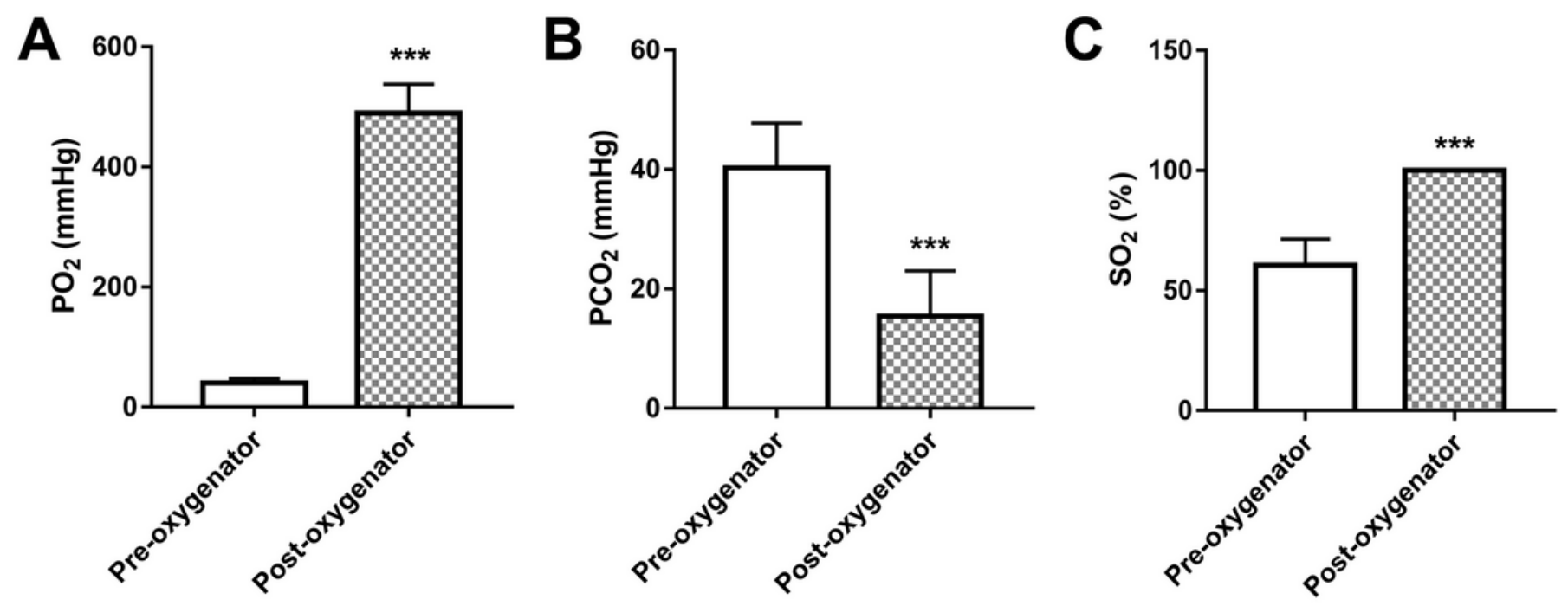

Figure 3

Blood gas analysis was performed to ensure proper function of the oxygenator $(n=7)$. PO2 (A), PCO2 (B), andSO2 (C). ${ }^{* * *} \mathrm{p}<0.001$.
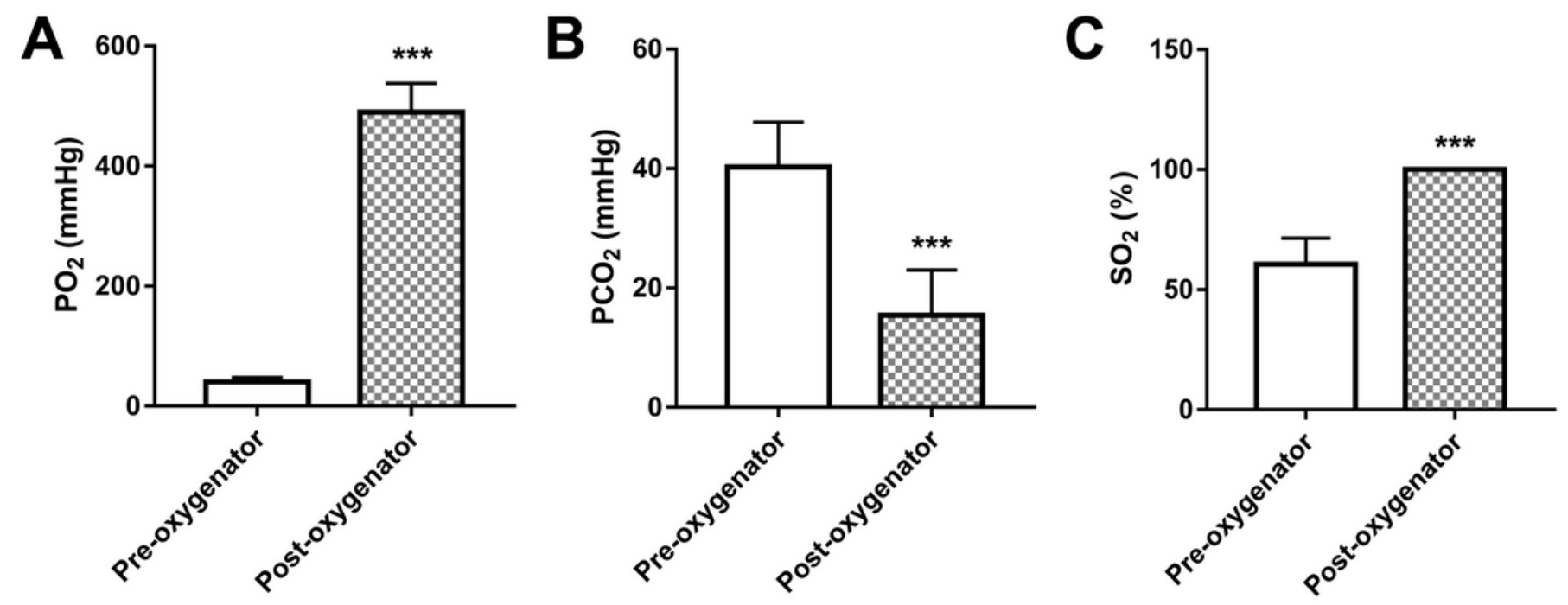

Figure 3

Blood gas analysis was performed to ensure proper function of the oxygenator $(n=7)$. PO2 (A), PCO2 (B), andSO2 (C). ${ }^{* \star *} \mathrm{p}<0.001$. 

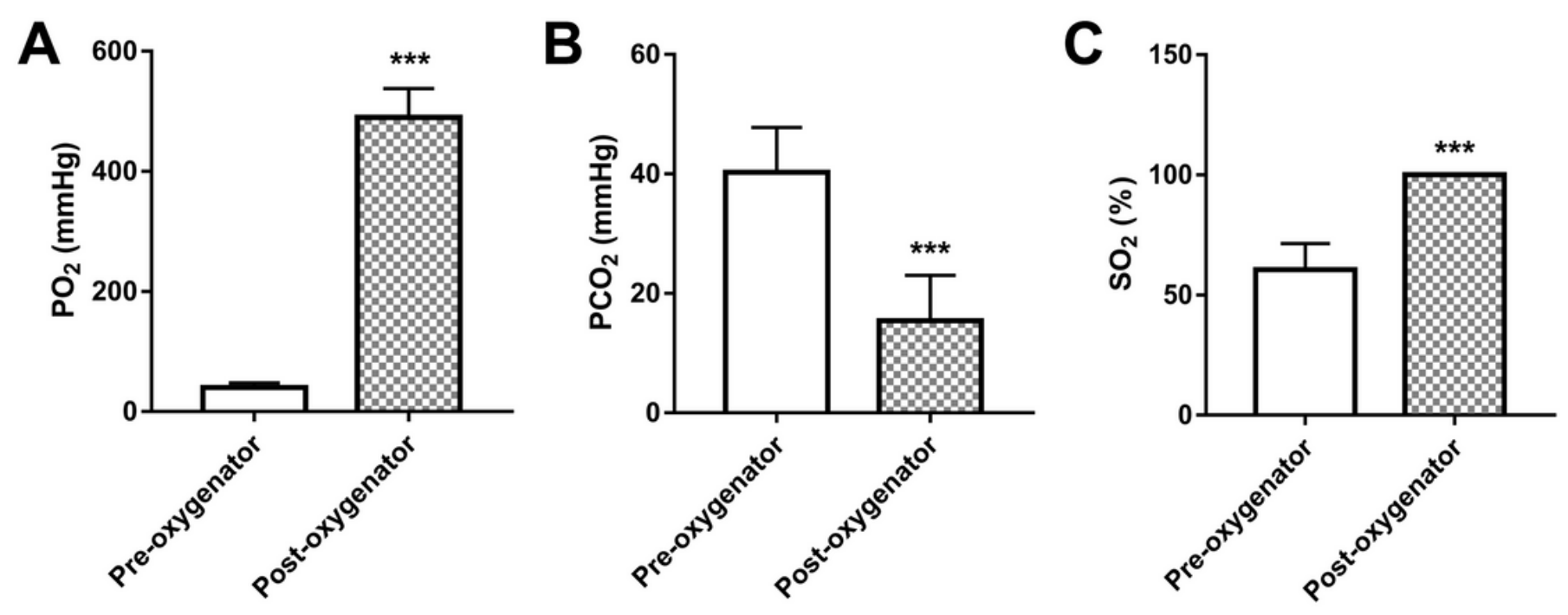

Figure 3

Blood gas analysis was performed to ensure proper function of the oxygenator $(n=7)$. PO2 (A), PCO2 (B), andSO2 (C). ${ }^{* *} \mathrm{p}<0.001$.

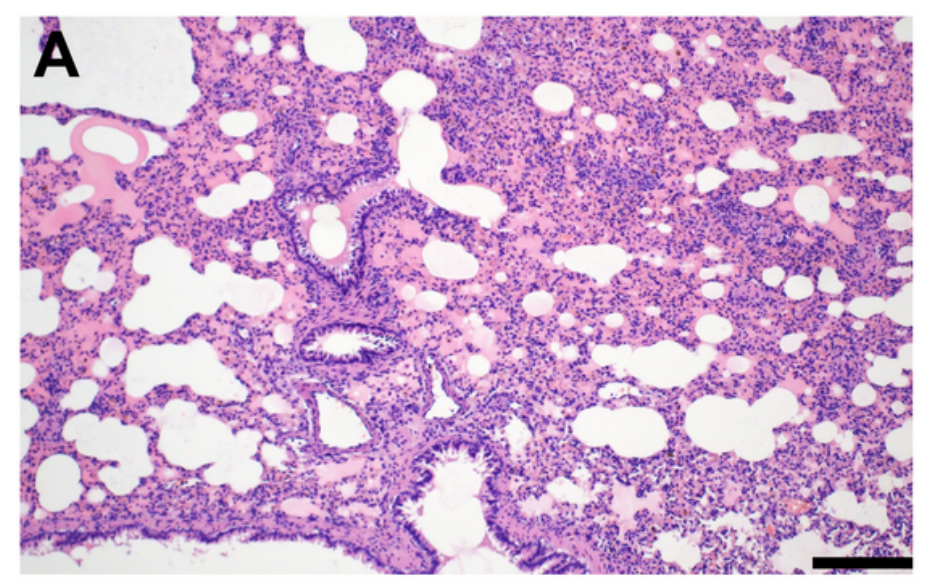

OA

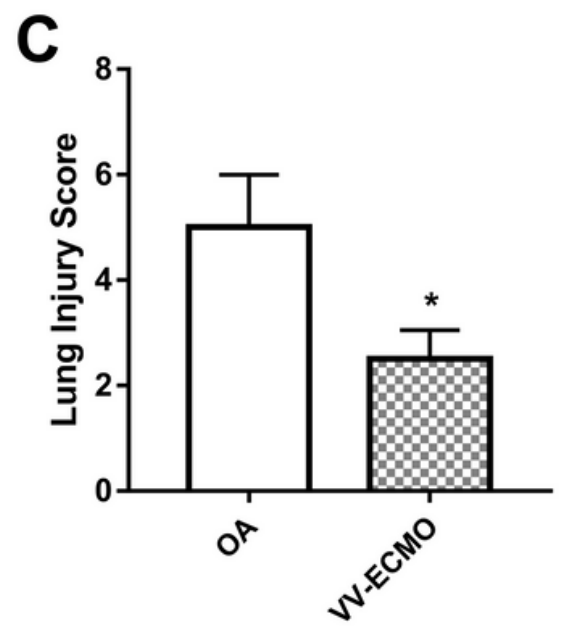

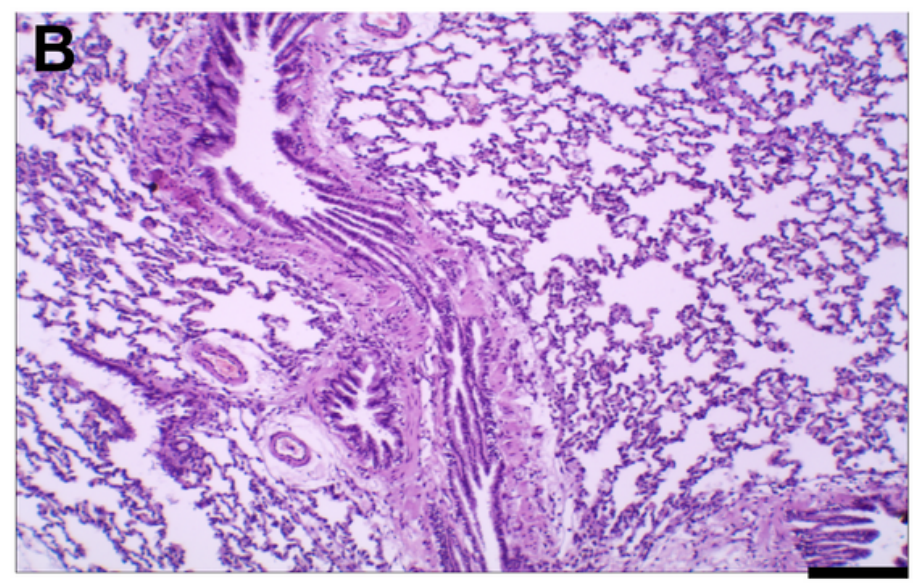

VV-ECMO
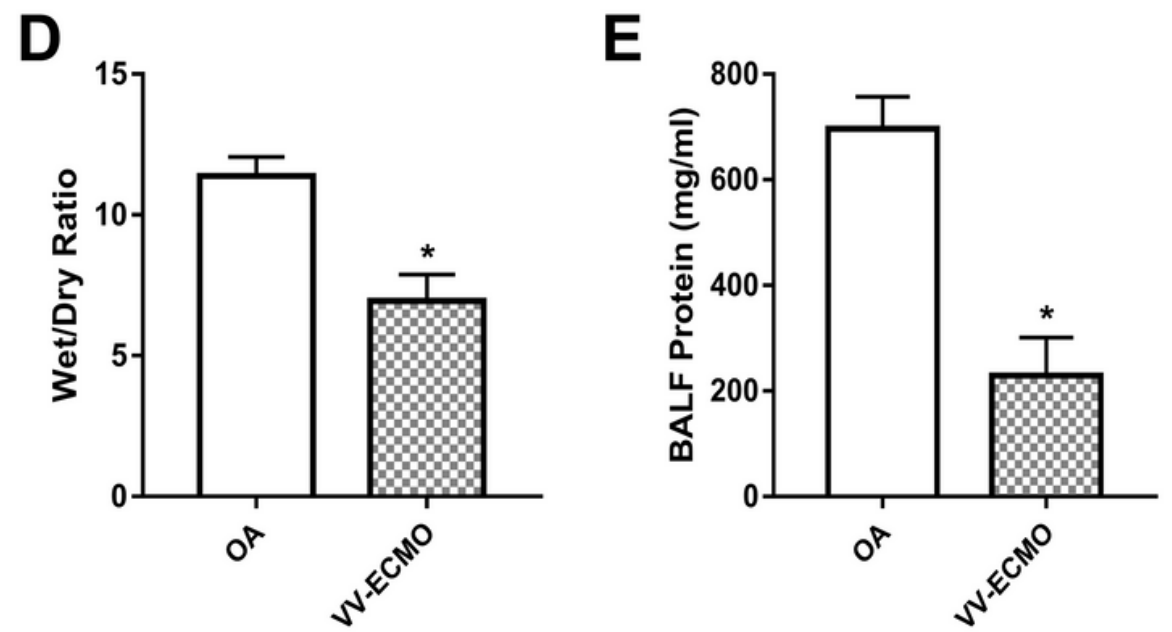

Figure 4 
Histologic evaluation of lung sections. Severe alveolar hemorrhagic edema and infiltration of inflammatory cells in the oleic acid (OA) group, scale bar $=100 \mathrm{~mm}(\mathrm{~A})$. VV-ECMO attenuated the lung pathology (B). Lung injury was quantified by a validated score (C). Wet/dry weight ratio obtained from the left lungs of the two groups (D). VV-ECMO decreased in lung capillary-alveolar leakage as measured by BALF protein content $(\mathrm{E}) .{ }^{*} \mathrm{p}<0.05$.
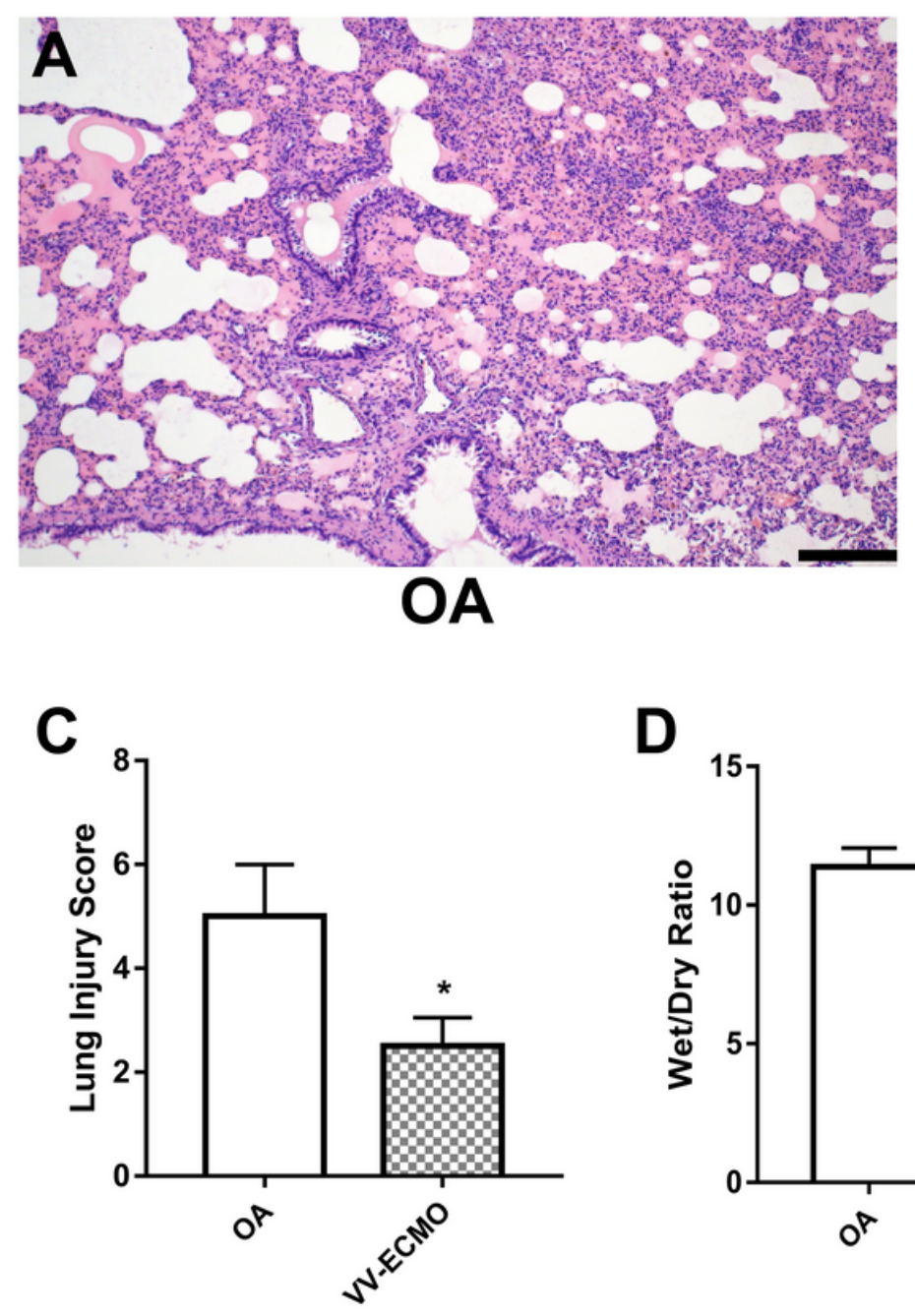

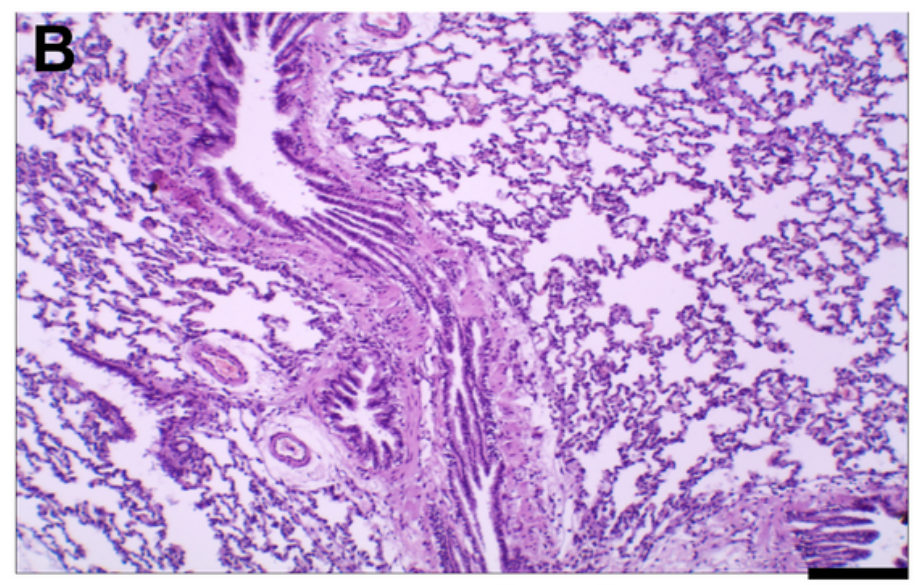

VV-ECMO
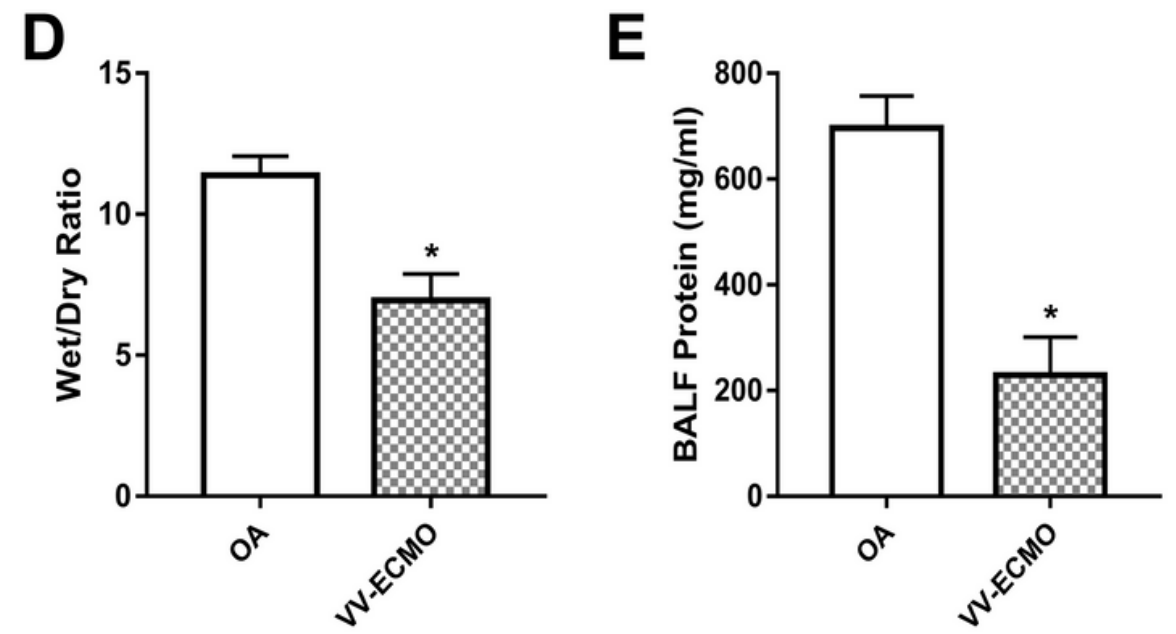

Figure 4

Histologic evaluation of lung sections. Severe alveolar hemorrhagic edema and infiltration of inflammatory cells in the oleic acid (OA) group, scale bar $=100 \mathrm{~mm}(\mathrm{~A})$. VV-ECMO attenuated the lung pathology (B). Lung injury was quantified by a validated score (C). Wet/dry weight ratio obtained from the left lungs of the two groups (D). VV-ECMO decreased in lung capillary-alveolar leakage as measured by BALF protein content $(\mathrm{E}) .{ }^{*} \mathrm{p}<0.05$. 


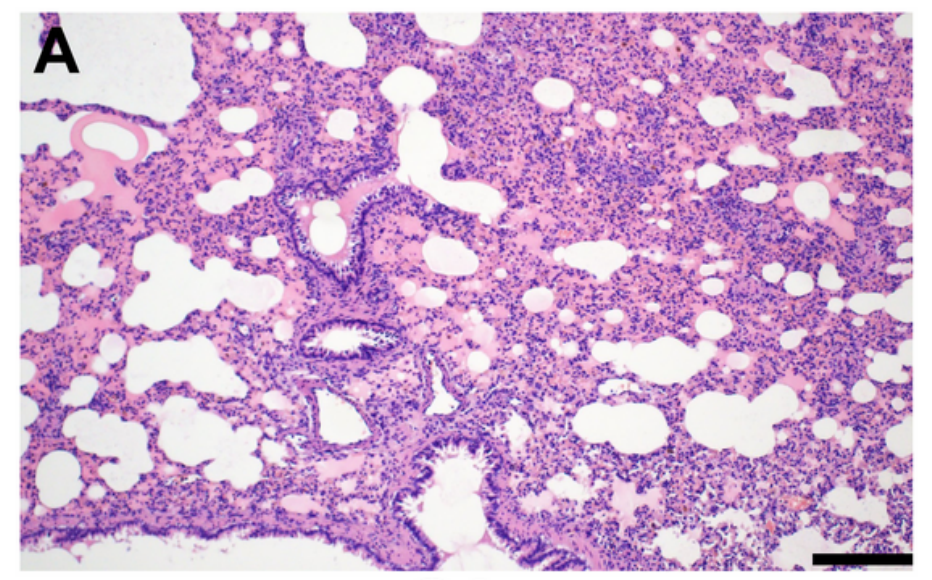

OA
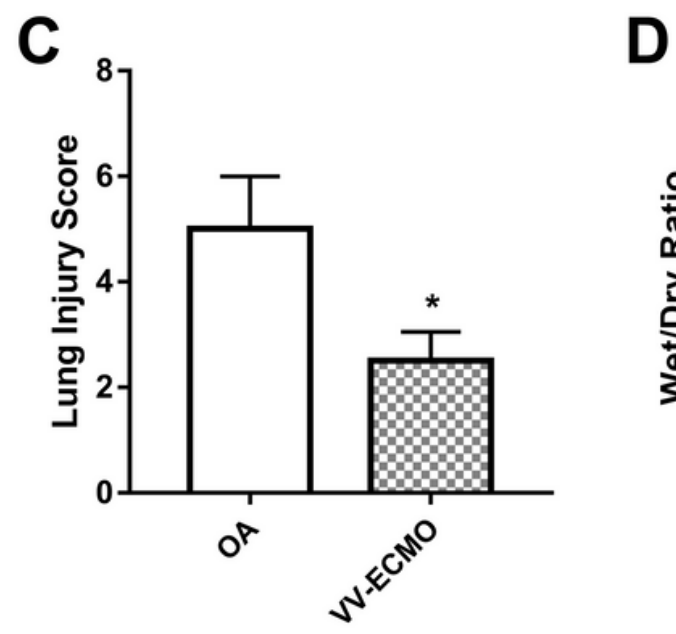

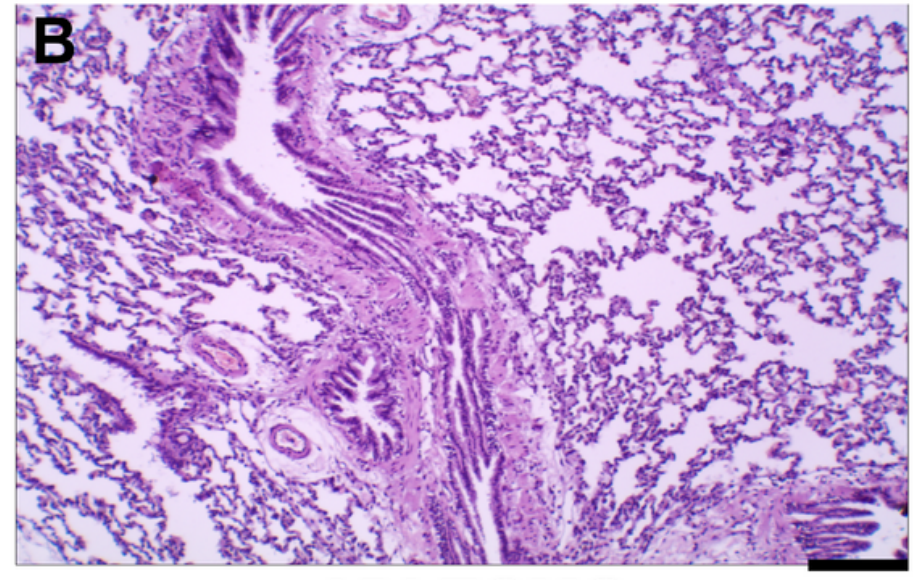

VV-ECMO

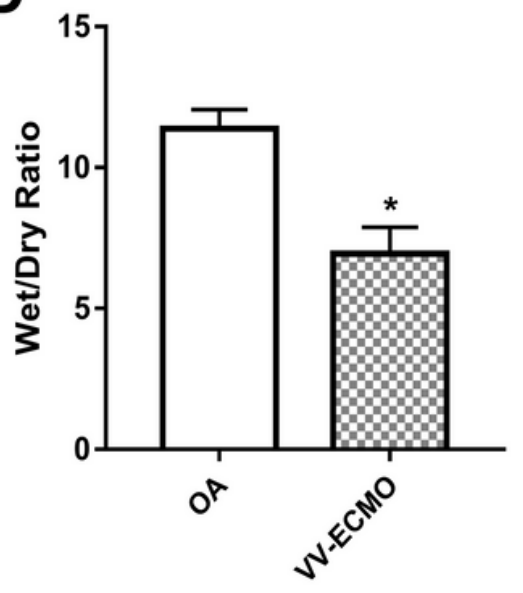

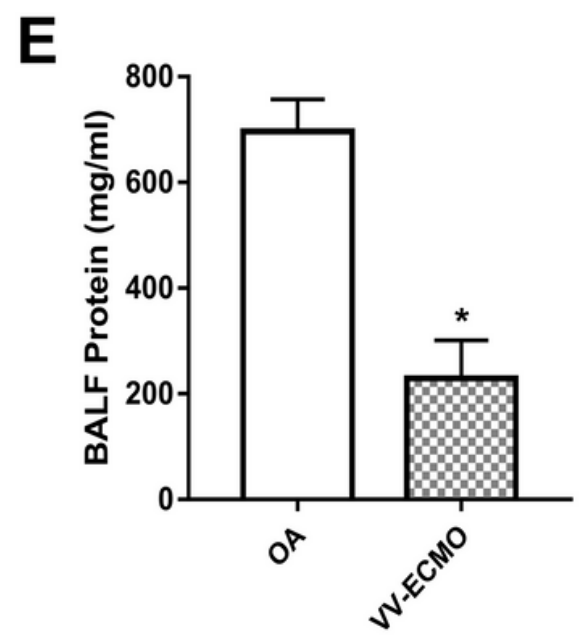

Figure 4

Histologic evaluation of lung sections. Severe alveolar hemorrhagic edema and infiltration of inflammatory cells in the oleic acid (OA) group, scale bar $=100 \mathrm{~mm}(\mathrm{~A}) . \mathrm{VV}$-ECMO attenuated the lung pathology (B). Lung injury was quantified by a validated score (C). Wet/dry weight ratio obtained from the left lungs of the two groups (D). VV-ECMO decreased in lung capillary-alveolar leakage as measured by BALF protein content $(E) .{ }^{*} p<0.05$.

\section{Supplementary Files}

This is a list of supplementary files associated with this preprint. Click to download.

- Additionalfile1.mp4

- Additionalfile1.mp4

- Additionalfile1.mp4

- Additionalfile.docx 
- Additionalfile.docx

- Additionalfile.docx 